Cite this: Phys. Chem. Chem. Phys., 2013, 15, 16774

Received 27th May 2013,

Accepted 22nd August 2013

DOI: $10.1039 / c 3 c p 52233 d$

www.rsc.org/pccp

\title{
Nitrogen-enriched carbon electrodes in electrochemical capacitors: investigating accessible porosity using CM-SANS†
}

\begin{abstract}
Anthony J. R. Rennie* and Peter J. Hall
Carbon electrochemical capacitor electrodes containing nitrogen groups were studied with respect to their electrochemical behaviour, chemical composition and physical characteristics. Thermal treatment of nitrogen-enriched carbon materials in different atmospheres was used to control the specific type and concentration of nitrogen groups present, while importantly retaining similar pore size distributions. Pyridinic nitrogen is shown to be most likely responsible for increased values of surface area normalized specific capacitance, although the mechanisms by which this occurs are poorly understood. Contrast matched-small angle neutron scattering (CM-SANS) was employed to probe the electrode porosity accessible to an electrolyte and indicates that there is no appreciable difference between the materials studied. Cyclic Voltammetry showed no evidence of electrode reactions occurring over the operating potential range. Therefore a greater amount of charge is displaced at pyridinic sites during the chargedischarge process. This may occur due to a specific adsorption mechanism, coupled with enhanced electron conductivity through the carbon matrix.
\end{abstract}

\section{Introduction}

Electrochemical capacitors (ECs), also referred to as supercapacitors, are electrical energy storage devices that absorb and release charge at relatively high rates when compared with electrochemical cells. ${ }^{1}$ In addition to high power density, they exhibit exceptionally long cycle lives and high efficiency, enabling them to complement batteries and fuel cells in systems where there is a substantial difference between peak and average power demands (e.g. in electric vehicles). ${ }^{2}$

Charge is stored through two main mechanisms; electrical double-layer capacitors (EDLCs) store charge electrostatically at the interface between electrode surfaces and electrolyte ions, whereas pseudocapacitance is more akin to the processes that occur in battery electrodes. ${ }^{1,3,4}$ The most commonly used electrode materials in EDLCs are activated carbons, ${ }^{4-8}$ due to their combination of electrical conductivity, high specific surface area (SSA) and the porous structure of carbon materials can be tailored to better accommodate specific electrolyte ions. ${ }^{9}$ In addition, the capacitance associated with some activated carbons has been shown to include a significant contribution

Dept. of Chem. \& Bio. Eng., University of Sheffield, Sheffield, S1 3JD, UK. E-mail: a.rennie@sheffield.ac.uk; Fax: +44 (0)114 222 7501;

Tel: +44(0)1142228257

$†$ Electronic supplementary information (ESI) available: Experimental details, Nyquist plots, deconvoluted X-ray photoelectron spectra and Porod invariant calculation. See DOI: 10.1039/c3cp52233d through pseudocapacitive reactions involving oxygen containing functional groups, ${ }^{10}$ which has inspired research into the effects of incorporating alternative heteroatoms into the carbon matrix.

Several studies have concluded that the inclusion of nitrogen atoms into the carbon electrode structure can enhance the performance of ECs, ${ }^{11-23}$ although it has been noted that the mechanism(s) by which this occurs are unclear. ${ }^{21}$ Proposed mechanisms include pseudocapacitive reactions involving electrolyte species, ${ }^{15,23,24}$ a larger surface area being rendered electrochemically active (through enhanced wettability of the electrode surface), ${ }^{13,16}$ and superior electron conduction through the carbon matrix due to the electron donor effect of certain nitrogen groups. $^{25}$

Reports generally normalize specific capacitances by a measure of surface area to account for changes in the double-layer component of the overall capacitance, ${ }^{18-22,26}$ however this approach is problematic when comparing materials with different pore and structural characteristics as normalized values for activated carbons are known to vary significantly. ${ }^{27,28}$ Also, capacitance measured on carbon surfaces can vary by up to an order of magnitude depending on the orientation of graphene planes, ${ }^{29}$ and it has been reported that the pore characteristics of the electrode exert substantial influence over specific capacitance. ${ }^{30}$

Nitrogen-enriched carbon materials (NECMs) are normally synthesized by impregnating a carbon (or carbon precursor) with nitrogen-containing organic compounds that subsequently decompose during thermal treatment. A further thermal treatment 
step under a reducing atmosphere was employed in this work to control both the concentration and type of nitrogen groups present, while retaining similar pore and structural characteristics. This approach substantially reduces the uncertainties associated with the process of surface area normalization. Furthermore this method removes the influence of electrochemically active surface oxygen groups, such as quinone, which can complicate the interpretation of electrochemical behaviour. Herein, we present work showing that the increased capacitance associated with NECMs is not due to increased surface accessibility through the use of contrast-matched small angle neutron scattering (CM-SANS). This technique is proposed as a unique tool for the investigation of inaccessible porosity in porous electrodes.

\section{Experimental}

Nitrogen-enriched carbon materials (NECMs) were produced by carbonisation, activation and further thermal treatment of a resorcinol-formaldehyde xerogel impregnated with $m$-phenylene diamine. The NECM produced after treatment under hydrogen is denoted as ' $\mathrm{C}-\mathrm{H}$ ', the material treated under an argon atmosphere as ' $\mathrm{C}-\mathrm{Ar}$ ', and that treated under a mixed atmosphere as ' $\mathrm{C}-\mathrm{HAr}$ '.

Nitrogen adsorption-desorption isotherms at $77 \mathrm{~K}$ were obtained using a Micromeritics ASAP 2420 instrument; samples were degassed at $200{ }^{\circ} \mathrm{C}$ for $10 \mathrm{~h}$ before analysis. Elemental analysis was performed using a Perkin Elmer 2400 Series II CHNS/O Elemental Analyser, and proximate analysis was performed using a Mettler Toledo TGA/DSC1 STARe instrument. XPS was performed in an ion pumped VG Microtech CLAM 4 MCD analyser system using $200 \mathrm{~W}$ unmonochromated Mg X-ray excitation (1253.6 eV).

Small-angle neutron scattering (SANS) was performed using the LOQ small-angle diffractometer at the ISIS Pulsed Neutron Source (STFC Rutherford Appleton Laboratory, Didcot, U.K.). ${ }^{31,32}$ Deuterium oxide was identified as a suitable contrast matching liquid by calculating the scattering length density of the NECMs.

Electrodes were manufactured by mixing the NECM under study with polymer binder (KynarFlex) and milled carbon black (Vulcan XC72), in an 80/10/10 ratio by mass. Symmetric twoelectrode EC cells were constructed using a version of a test cell used in previous investigations, ${ }^{9}$ and employing potassium hydroxide solution (28.5 wt\%) as electrolyte.

Electrochemical tests were carried out using a Solartron Analytical 1470E Multichannel Potentiostat/Galvanostat with 1455A Frequency Response Analyser. Cell temperature was maintained at $25{ }^{\circ} \mathrm{C}\left( \pm 0.1{ }^{\circ} \mathrm{C}\right)$. Cells were cycled between 0.0 and $1.0 \mathrm{~V}$ ( $v s$. OCP) Galvanostatically at various rates between 0.1 and $c a .12 \mathrm{~A} \mathrm{~g}^{-1}$. Electrochemical impedance spectra were obtained at a potential bias of $0.1 \mathrm{~V}$ (vs. OCP) using a $10 \mathrm{mV}$ perturbation over the frequency range $100 \mathrm{kHz}$ to $10 \mathrm{MHz}$. Cyclic Voltammetry was performed between 0.0 and $1.0 \mathrm{~V}$ (vs. OCP) at sweep rates of $10 \mathrm{mV} \mathrm{s}^{-1}$ and $100 \mathrm{mV} \mathrm{s}^{-1}$. Specific capacitance values are based on the mass of dry, ash-free active material and are expressed on a three-electrode basis.
More details of the synthesis method, physical characterization, and electrochemical testing of the NECMs is given as (ESI $\dagger$ ).

\section{Results and discussion}

Nitrogen adsorption-desorption isotherms for the NECMs studied are shown in Fig. 1. The isotherms are a mixture of 'type I' and 'type IV' form ${ }^{33}$ although the uptake at low relative pressures differs for each sample indicating that micropore volume is dependent on the hydrogen concentration during thermal treatment. SSAs and pore characteristics for each sample derived from the isotherms are given in Table 1.

Although there is an increase in SSA and total pore volume with increasing hydrogen concentration during thermal treatment, these materials have similar pore characteristics, which allows for comparisons between their capacitances to be made on a surface area normalised basis. The chemical composition of the samples determined using both combustive elemental analysis and X-ray photoelectron spectroscopy (XPS), a surface specific technique, are given in Table 2.

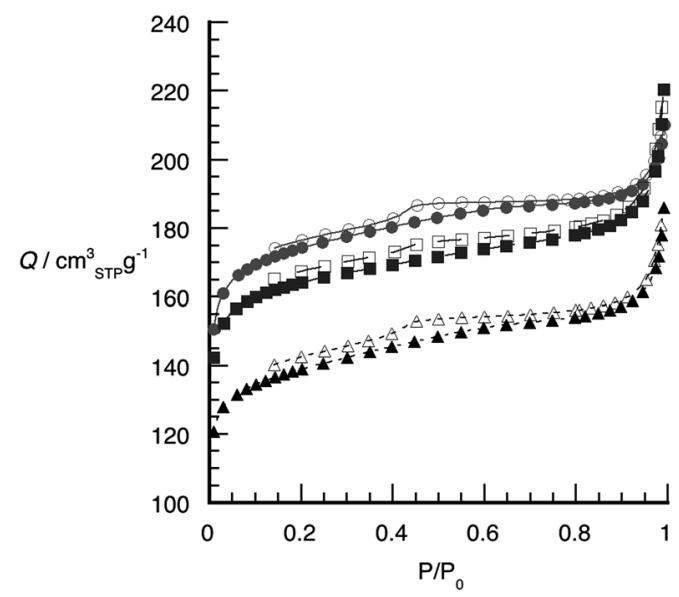

Fig. 1 Nitrogen sorption isotherms (at $77 \mathrm{~K}$ ) of NECMs. Circles: NECM treated under hydrogen $(\mathrm{C}-\mathrm{H})$, squares: mixed hydrogen-argon atmosphere $(\mathrm{C}-\mathrm{HAr})$, triangles: argon (C-Ar).

Table 1 Specific surface areas and pore characteristics calculated from nitrogen sorption isotherms at $77 \mathrm{~K}$. (NECM treated under hydrogen ' $\mathrm{C}-\mathrm{H}^{\prime}$, argon ' $\mathrm{C}-\mathrm{Ar}$ ', mixed atmosphere ' $\mathrm{C}-\mathrm{HAr}$ ')

\begin{tabular}{|c|c|c|c|c|c|c|c|}
\hline & $\begin{array}{l}\mathrm{SSA}^{a} \\
{\left[\mathrm{~m}^{2} \mathrm{~g}^{-1}\right]}\end{array}$ & $\begin{array}{l}V_{\mathrm{tot}}{ }^{b} \\
{\left[\mathrm{~cm}^{3} \mathrm{~g}^{-1}\right]}\end{array}$ & $\begin{array}{l}V_{\mathrm{mi}_{-\mathrm{t}}}{ }^{c} \\
{\left[\mathrm{~cm}^{3} \mathrm{~g}^{-1}\right]}\end{array}$ & $\begin{array}{l}V_{\mathrm{mi}-\mathrm{DR}}{ }^{d} \\
{\left[\mathrm{~cm}^{3} \mathrm{~g}^{-1}\right]}\end{array}$ & $\begin{array}{l}V_{\text {meso }}{ }^{e} \\
{\left[\mathrm{~cm}^{3} \mathrm{~g}^{-1}\right]}\end{array}$ & $\begin{array}{l}d_{\mathrm{av}}{ }^{f} \\
{[\mathrm{~nm}]}\end{array}$ & $\begin{array}{l}d_{\mathrm{M}}^{g} \\
{[\mathrm{~nm}]}\end{array}$ \\
\hline $\mathrm{C}-\mathrm{H}$ & 580 & 0.33 & 0.22 & 0.24 & 0.08 & 2.3 & 1.4 \\
\hline C-HAr & 535 & 0.33 & 0.21 & 0.23 & 0.08 & 2.4 & 1.4 \\
\hline $\mathrm{C}-\mathrm{Ar}$ & 465 & 0.28 & 0.18 & 0.21 & 0.08 & 2.4 & 1.4 \\
\hline
\end{tabular}

${ }^{a}$ Specific surface area calculated using the BET method. ${ }^{b}$ Total pore volume calculated at $\mathrm{P} / \mathrm{P}_{0}>0.95 .{ }^{c}$ Micropore volume determined using the t-plot method. ${ }^{d}$ Micropore volume determined using the Dubinin-Astakhov method. ${ }^{e}$ Average pore width was estimated using the relationship $4 V_{\text {tot }} /$ SSA. ${ }^{f}$ Mesopore volume evaluated using the Barrett-Joyner-Halenda (BJH) method on the adsorption branch of the isotherms. ${ }^{g}$ Modal pore width calculated from the obtained form of the Dubinin-Astakhov equation using the equation proposed by Medek. 
Table 2 Elemental composition of NECMs. (NECM treated under hydrogen ' $\mathrm{C}-\mathrm{H}$ ', argon ' $\mathrm{C}-\mathrm{Ar}^{\prime}$ ', mixed atmosphere ' $\mathrm{C}-\mathrm{HAr}$ ')

\begin{tabular}{|c|c|c|c|c|c|c|}
\hline & \multicolumn{3}{|c|}{ Elemental analysis $^{a}$} & \multicolumn{3}{|c|}{ X-ray photoelectron spectroscopy ${ }^{b}$} \\
\hline & $\mathrm{C}[\mathrm{wt} \%]$ & $\mathrm{H}[\mathrm{wt} \%]$ & $\mathrm{N}[\mathrm{wt} \%]$ & $\mathrm{C}[\mathrm{at} \%]$ & $\mathrm{N}[\mathrm{at} \%]$ & $\mathrm{O}[\mathrm{at} \%]$ \\
\hline $\mathrm{C}-\mathrm{H}$ & 93.4 & 0.5 & 1.1 & 92.1 & 0.8 & 6.5 \\
\hline C-HAr & 95.8 & 0.8 & 1.7 & 93.6 & 1.1 & 5.0 \\
\hline $\mathrm{C}-\mathrm{Ar}$ & 91.0 & 0.4 & 2.3 & 92.3 & 1.9 & 5.5 \\
\hline
\end{tabular}

Nitrogen content is seen to decrease with increasing hydrogen concentration indicating that thermal treatment under hydrogen is a useful technique by which to control the amount of nitrogen groups in NECMs. Table 2 also shows that $\mathrm{C}-\mathrm{H}$ possesses the lowest nitrogen content while displaying the largest micropore volume, therefore the abstraction of nitrogen groups is accompanied by the evolution of accessible porosity. Nitrogen content was then divided into the groups illustrated in Fig. 2 by deconvolution of detailed XPS scans and is expressed as an absolute surface concentration in Table 3.

Table 3 shows that the gas used in the thermal treatment process not only controls the amount of nitrogen in the NECMs but can also be used to control the concentration of specific nitrogen groups. By comparing the composition of $\mathrm{C}-\mathrm{H}$ and $\mathrm{C}-\mathrm{Ar}$ it is seen that the reduction is attributable to the removal of $\mathrm{N}-5$ and N-6 type groups. Table 2 also shows that a considerable amount of oxygen atoms are present in the materials, however detailed XPS scans show that the oxygen content is not in the form of electrochemically active quinone groups.

Small-angle neutron scattering (SANS) has been employed to investigate the pore characteristics of carbon materials used in $\mathrm{ECs}^{34}$ and is especially suited to the study of materials that possess microporosity. ${ }^{35}$ Additionally, the technique of contrastmatched SANS has been used to identify the degree of closed porosity in porous carbon materials ${ }^{36}$ and has been applied in this work to investigate the amount of porosity accessible to an electrolyte. It is proposed that any increase in electrochemically

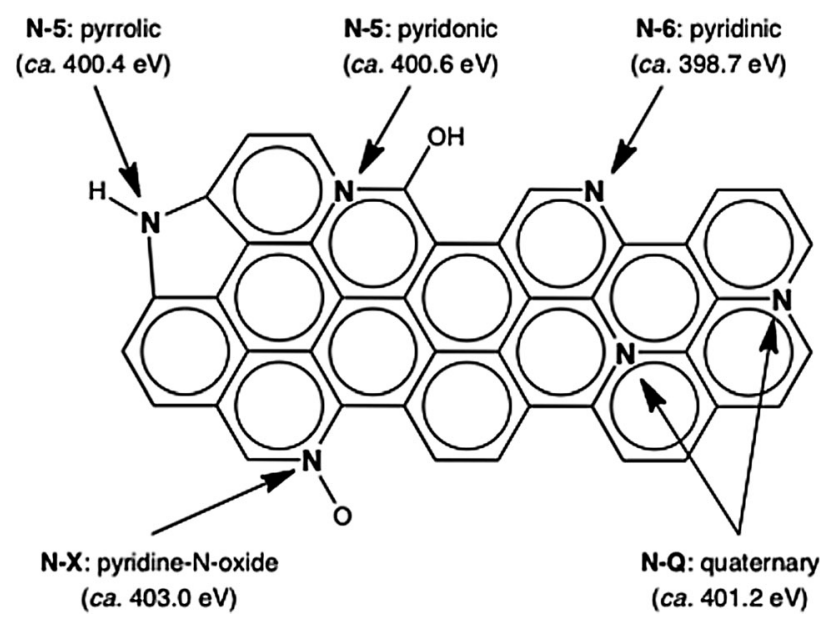

Fig. 2 Nitrogen groups found in NECMs with corresponding XPS binding energies. $^{12}$
Table 3 Absolute concentration of nitrogen groups present in NECMs. (NECM treated under hydrogen ' $\mathrm{C}-\mathrm{H}^{\prime}$, argon ' $\mathrm{C}-\mathrm{Ar}^{\prime}$, mixed atmosphere ' $\mathrm{C}-\mathrm{HAr}$ ')

\begin{tabular}{lllll}
\hline & $\mathrm{N}-5^{a}[\mathrm{at} \%]$ & $\mathrm{N}-6^{b}[\mathrm{at} \%]$ & $\mathrm{N}-\mathrm{Q}^{c}[\mathrm{at} \%]$ & $\mathrm{N}-\mathrm{X}^{d}[\mathrm{at} \%]$ \\
\hline $\mathrm{C}-\mathrm{H}$ & 0.11 & 0.09 & 0.45 & 0.15 \\
$\mathrm{C}-\mathrm{HAr}$ & 0.24 & 0.13 & 0.53 & 0.21 \\
$\mathrm{C}-\mathrm{Ar}$ & 0.73 & 0.52 & 0.41 & 0.24
\end{tabular}

${ }^{a} 400.6 \pm 0.1 \mathrm{eV}^{b} 398.7 \pm 0.1 \mathrm{eV}^{c}{ }^{c} 401.2 \pm 0.1 \mathrm{eV} .{ }^{d} 403.0 \pm 0.3 \mathrm{eV}$

active surface area resulting from the presence of nitrogen groups would appear as a difference in the scattering behaviour of a sample that has been impregnated with a liquid of the same scattering length density. For the NECMs studied, the calculated scattering length density of the samples almost identical to that of deuterium oxide, which was employed as a suitable analogue to the aqueous electrolyte used in electrochemical testing.

The difference in scattering cross section between the $d r y$ and contrast matched carbon materials (of up to three orders of magnitude) seen in Fig. 3 confirms that an excellent degree of contrast matching was obtained.

For each of the NECMs, the SANS plots in Fig. 3 are of a similar form which confirms that their pore characteristics are comparable. For values of scattering wave vector $(q)$ greater than $0.1 \AA^{-1}$, corresponding to the micropore region, ${ }^{37}$ both $\mathrm{C}-\mathrm{H}$ and $\mathrm{C}-\mathrm{HAr}$ exhibit a greater amount of scattering in comparison with $\mathrm{C}-\mathrm{Ar}$, which correlates well with the micropore volumes presented in Table 1. Further analysis of the SANS data confirms the trend in SSA seen in Table 1 (see ESI $\dagger$ ). Where scattering occurs purely due to micropores there remains a difference between the $d r y$ and contrast-matched scattering curves, which confirms that even the smallest pores in each NECM are open and filled by the contrast-matching fluid. There is no discernable difference in the scattering between the contrast-matched plots that could be attributed to the presence of nitrogen groups, and it is therefore unlikely that any changes in capacitance between NECMs are due to an increased electrochemically active surface area arising from an increase in surface wettability.

Symmetrical two-electrode cells were constructed using the NECMs and aqueous potassium hydroxide solution electrolyte. Cells were tested using electrochemical impedance spectroscopy, obtained spectra are given as ESI. $\nmid$ Parameters derived from the spectra are presented in Table 4.

$\mathrm{C}-\mathrm{H}$ could be expected to produce the largest specific capacitance through the EDLC mechanism by possessing the highest SSA, however C-Ar exhibited the highest specific capacitance confirming that nitrogen heteroatoms can have a beneficial effect on the capacitance. However, polarization resistance also increases with nitrogen content and therefore a trade-off exists between increased capacitance and an increased equivalent series resistance (and therefore reduced power density).

When specific capacitance is normalized on the basis of SSA, the influence of nitrogen content becomes clearer as the two samples that contain a low concentration of edge nitrogen groups have a similar value, whereas $\mathrm{C}-\mathrm{Ar}$, which has a significantly larger concentration of edge nitrogen groups, has a value of $20.3 \mu \mathrm{F} \mathrm{cm}^{-2}$. The finding that an increased surface area normalized specific 

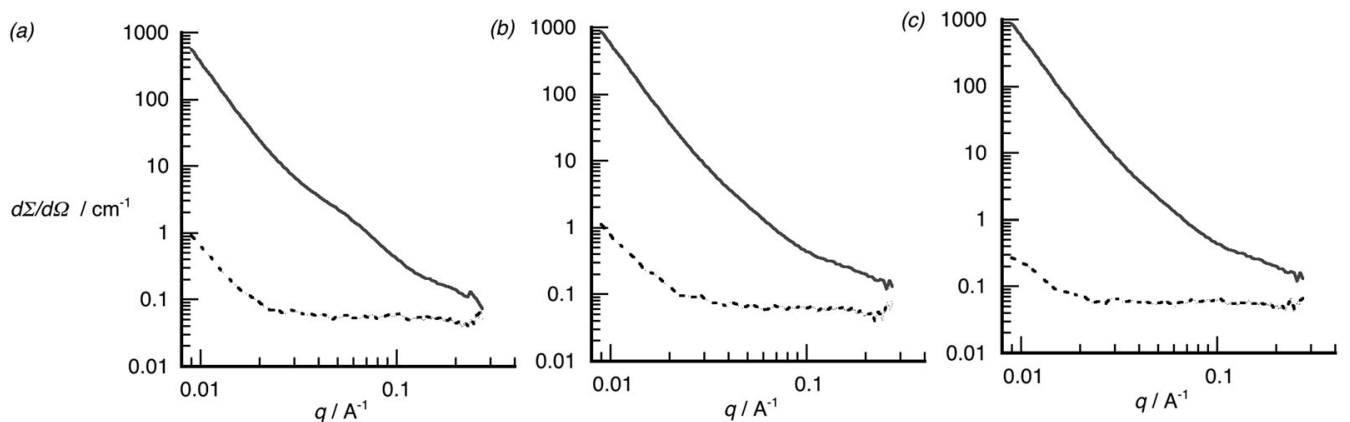

Fig. 3 Small angle neutron scattering (solid lines) and contrast matched small angle neutron scattering (dashed lines) plots for (a) NECM treated under argon (C-Ar), (b) NECM treated under a hydrogen-argon mixed atmosphere (C-HAr) and (c) NECM treated under hydrogen (C-H)

Table 4 Characteristics determined by fitting Randles' circuit to EIS data for NECMs. (NECM treated under hydrogen ' $\mathrm{C}-\mathrm{H}$ ', argon ' $\mathrm{C}-\mathrm{Ar}$ ', mixed atmosphere 'C-HAr')

\begin{tabular}{lllll}
\hline & $c^{a}\left[\mathrm{~F} \mathrm{~g}^{-1}\right]$ & $c_{\mathrm{nSSA}}{ }^{b}\left[\mu \mathrm{F} \mathrm{cm}^{-2}\right]$ & $R_{\mathrm{s}}{ }^{c}\left[\Omega \mathrm{cm}^{-2}\right]$ & $R_{\mathrm{p}}{ }^{c}\left[\Omega \mathrm{cm}^{-2}\right]$ \\
\hline C-H & 85.4 & 14.7 & 0.07 & 0.03 \\
C-HAr & 76.1 & 14.2 & 0.07 & 0.04 \\
C-Ar & 94.5 & 20.3 & 0.07 & 0.06
\end{tabular}

${ }^{a}$ Specific capacitance determined at $10 \mathrm{MHz}$ and expressed on a threeelectrode basis using the active mass of NECM. ${ }^{b}$ Specific capacitance normalized on the basis of surface area SSA given in Table $2 .^{c}$ Series resistance $\left(R_{\mathrm{S}}\right)$ and polarization resistance $\left(R_{\mathrm{p}}\right)$ determined by fitting Randles' circuit ${ }^{38}$ to the impedance spectra (see ESI).

capacitance is associated with greater nitrogen contents is in agreement with several reports.

Moreover, by considering the concentration of the nitrogen groups present, the best correlation is found with the pyridinic form of nitrogen (N-6). It is therefore likely that the increase in capacitance is specifically associated with pyridinic nitrogen (N-6). This can be asserted due to the different nitrogen groups classified as N-5 type, which are found at a binding energy of $400.6 \mathrm{eV}$. The situation whereby pyrollic nitrogen and the tautomeric forms of pyridonic nitrogen found at this binding energy behave in an identical manner electrochemically, is far less likely than the situation where pyridinic nitrogen is responsible for the larger surface area normalized specific capacitance observed.

Specific capacitance was also determined under Galvanostatic discharge over a range of current densities and the results are presented in Fig. 4. Capacitance values determined at relatively low rates are in agreement with those determined using EIS. The surface area normalized values of specific capacitance in Fig. 4 are higher for $\mathrm{C}-\mathrm{Ar}$ at all of the rates studied than the samples possessing very little pyridinic nitrogen. The fact that the there is no rate dependence of this effect could indicate that reactions involving N-6 groups do contribute to the overall capacitance of the electrode.

In order to determine whether any potential dependent reactions influence the electrochemical behaviour of the samples Cyclic Voltammetry (CV) was performed in symmetrical twoelectrode cells. Electrodes exploiting known pseudocapacitive reactions (e.g. metal oxides, ${ }^{1}$ quinone/hydroquinone ${ }^{10,26}$ ) usually produce peaks in CVs over a voltage range of roughly $400 \mathrm{mV}$.

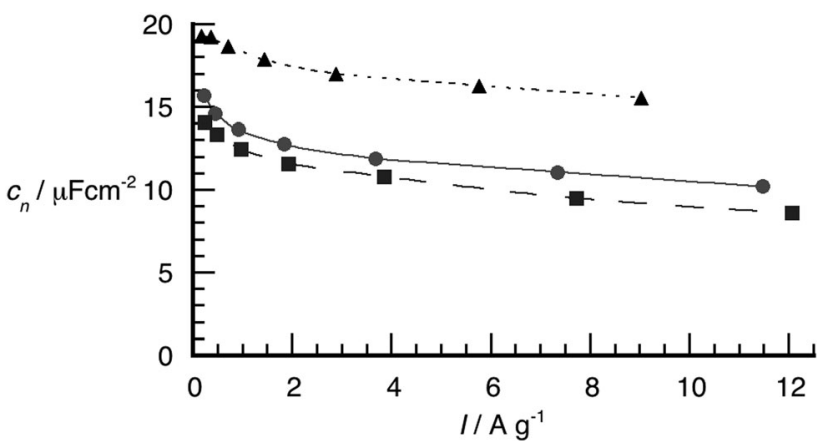

Fig. 4 Normalized Galvanostatic discharge capacitance against specific discharge current. Circles: NECM treated under hydrogen $(\mathrm{C}-\mathrm{H})$, squares: mixed hydrogen-argon atmosphere ( $\mathrm{C}-\mathrm{HAr})$, triangles: argon (C-Ar).
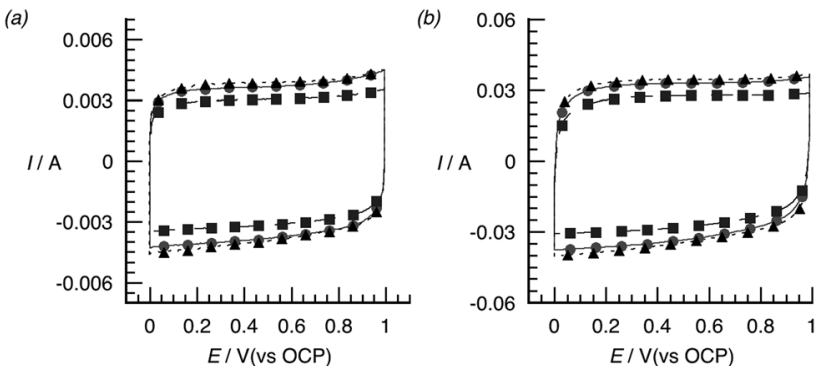

Fig. 5 Cyclic Voltammograms at (a) $10 \mathrm{mV} \mathrm{s}^{-1}$ and (b) $100 \mathrm{mV} \mathrm{s}^{-1}$. Current is normalized based on the mass of NECM. Circles: NECM treated under hydrogen $(\mathrm{C}-\mathrm{H})$, squares: mixed hydrogen-argon atmosphere ( $C-H A r)$, triangles: argon ( $C-A r)$.

Fig. 5(a) and (b) however show a rectangular form for all samples, which is typically associated with the EDLC mechanism. As no changes in the rate of charge acceptance with changes in voltage were obtained during $\mathrm{CV}$, it unlikely that a potential dependent redox mechanism occurs.

\section{Conclusions}

NECMs treated in the presence of hydrogen were used to investigate the mechanisms by which nitrogen groups influence the electrochemical behaviour of EC electrodes. CM-SANS experiments indicate that there is no discernable difference in electrolyte 
accessibility between the NECMs studied and CV showed no evidence of electrode reactions occurring over the operating potential range. CM-SANS could be an extremely useful technique by which to study electrolyte accessibility in systems where there is interaction between electrodes and liquid electrolytes (e.g. batteries, dye-sensitized solar cells etc.). Electrochemical methods confirmed that nitrogen groups can have a beneficial effect on specific capacitance, and it was concluded that pyridinic nitrogen ( $\mathrm{N}-6)$ in particular is likely to be responsible for this effect. It is proposed that a greater amount of charge is displaced at pyridinic sites during the charge-discharge process, and that a specific adsorption mechanism coupled with enhanced electron conductivity through the carbon matrix is responsible for this effect.

\section{Acknowledgements}

This work was supported by the UK's EPSRC Supergen Energy Storage Consortium. (EP/H019596/1). The authors thank the STFC and Dr S. Rogers (instrument scientist at LOQ).

\section{Notes and references}

1 B. E. Conway, Electrochemical Supercapacitors: Scientific Fundamentals and Technological Applications, Kluwer Academic/ Plenum Publishers, New York, 1999.

2 R. Kötz and M. Carlen, Electrochim. Acta, 2000, 45, 2483-2498.

3 B. E. Conway, J. Electrochem. Soc., 1991, 138, 1539-1548.

4 P. J. Hall, M. Mirzaeian, S. I. Fletcher, F. B. Sillars, A. J. R. Rennie, G. O. Shitta-Bey, G. Wilson, A. Cruden and R. Carter, Energy Environ. Sci., 2010, 3, 1238.

5 E. Frackowiak and F. Béguin, Carbon, 2001, 39, 937-950.

6 A. G. Pandolfo and A. F. Hollenkamp, J. Power Sources, 2006, 157, 11-27.

7 P. Simon and Y. Gogotsi, Nat. Mater., 2008, 7, 845-854.

8 V. V. N. Obreja, Physica E, 2008, 40, 2596-2605.

9 F. B. Sillars, S. I. Fletcher, M. Mirzaeian and P. J. Hall, Energy Environ. Sci., 2011, 4, 695.

10 H. A. Andreas and B. E. Conway, Electrochim. Acta, 2006, 51, 6510-6520.

11 K. Jurewicz, K. Babel, A. Ziólkowski, H. Wachowska and M. Kozlowski, Fuel Process. Technol., 2002, 77-78, 191-198.

12 K. Jurewicz, K. Babel, A. Ziólkowski and H. Wachowska, Electrochim. Acta, 2003, 48, 1491-1498.

13 K. Jurewicz, K. Babel, A. Ziólkowski and H. Wachowska, J. Phys. Chem. Solids, 2004, 65, 269-273.

14 E. Frackowiak, V. Khomenko, K. Jurewicz, K. Lota and F. Béguin, J. Power Sources, 2006, 153, 413-418.
15 E. Frackowiak, Phys. Chem. Chem. Phys., 2007, 9, 1774.

16 G. Lota, B. Grzyb, H. Machnikowska, J. Machnikowski and E. Frackowiak, Chem. Phys. Lett., 2005, 404, 53-58.

17 F. Béguin, K. Szostak, G. Lota and E. Frackowiak, Adv. Mater., 2005, 17, 2380-2384.

18 D. Hulicova, J. Yamashita, Y. Soneda, H. Hatori and M. Kodama, Chem. Mater., 2005, 17, 1241-1247.

19 D. Hulicova, M. Kodama and H. Hatori, Chem. Mater., 2006, 18, 2318-2326.

20 M. Seredych, D. Hulicova-Jurcakova, G. Q. Lu and T. J. Bandosz, Carbon, 2008, 46, 1475-1488.

21 D. Hulicova-Jurcakova, M. Kodama, S. Shiraishi, H. Hatori, Z. H. Zhu and G. Q. Lu, Adv. Funct. Mater., 2009, 19, 1800-1809.

22 E. J. Ra, E. Raymundo-Piñero, Y. H. Lee and F. Béguin, Carbon, 2009, 47, 2984-2992.

23 D.-W. Wang, F. Li, L.-C. Yin, X. Lu, Z.-G. Chen, I. R. Gentle, G. Q. (Max) Lu and H.-M. Cheng, Chem.-Eur. J., 2012, 18, 5345-5351.

24 E. Frackowiak, G. Lota, J. Machnikowski, C. Vix-Guterl and F. Béguin, Electrochim. Acta, 2006, 51, 2209-2214.

25 V. V. Strelko, V. S. Kuts and P. A. Thrower, Carbon, 2000, 38, 1499-1503.

26 D. Hulicova-Jurcakova, M. Seredych, G. Q. Lu and T. J. Bandosz, Adv. Funct. Mater., 2009, 19, 438-447.

27 H. Shi, Electrochim. Acta, 1996, 41, 1633-1639.

28 D. Qu and H. Shi, J. Power Sources, 1998, 74, 99-107.

29 J.-P. Randin and E. Yeager, J. Electrochem. Soc., 1971, 118, 711.

30 J. Chmiola, C. Largeot, P.-L. Taberna, P. Simon and Y. Gogotsi, Angew. Chem., Int. Ed., 2008, 47, 3392-3395.

31 http://www.isis.stfc.ac.uk/.

32 R. K. Heenan, J. Penfold and S. M. King, J. Appl. Crystallogr., 1997, 30, 1140-1147.

33 K. S. W. Sing, D. H. Everett, R. A. W. Haul, L. Moscou, R. A. Pierotti, J. Rouquerol and T. Siemieniewska, Pure Appl. Chem., 1985, 57, 603-619.

34 A. Braun, J. Kohlbrecher, M. Bärtsch, B. Schnyder, R. Kötz, O. Haas and A. Wokaun, Electrochim. Acta, 2004, 49, 1105-1112.

35 P. J. Hall, S. Brown, J. Fernandez and J. Calo, Carbon, 2000, 38, 1257-1259.

36 M. M. Antxustegi, P. J. Hall and J. M. Calo, J. Colloid Interface Sci., 1998, 202, 490-498.

37 J. M. Calo, P. J. Hall and M. Antxustegi, Colloids Surf., A, 2001, 187-188, 219-232.

38 J. E. B. Randles, Discuss. Faraday Soc., 1947, 1, 11. 